\title{
THE AUSTRALIAN INFORMATION SYSTEMS RESEARCH COMMUNITY: AN ANALYSIS OF MAINSTREAM PUBLICATION OUTLETS ${ }^{10}$
}

\author{
Gail Ridley', Paula Goulding ${ }^{2}$, Glenn Lowry ${ }^{3}$, Graham Pervan ${ }^{4}$ \\ ${ }^{1}$ School of Information Systems, University of Tasmania \\ Hobart Australia \\ email: Gail.Ridley@utas.edu.au \\ ${ }^{2}$ Department of Information Technology, Murdoch University \\ Perth Australia \\ ${ }^{3}$ College of Business Administration, University of Bahrain \\ State of Bahrain \\ ${ }^{4}$ School of Information Systems, Curtin University of Technology \\ Perth Australia
}

\begin{abstract}
This paper reports on an investigation of the nature of and interactions among the Information Systems academic research community in Australia. The 382 refereed papers from the two mainstream IS refereed publication outlets in Australia were analysed for the period 1990-1996 to determine the contributions of individual universities, departments and authors to the pattern of collaboration, and to examine the nature of the contributors. The study revealed that several institutions, departments and authors dominated the publication outlets and that the majority of the collaboration that occurred took place within university departments. Collaboration between and among different disciplines and nations, and between practitioners and academics was limited. It was found that although the Australian academic IS research community had only recently emerged, it was growing strongly.
\end{abstract}

\section{INTRODUCTION}

Information Systems (IS) is an emerging field with a short history that has been subject to the influence of many reference disciplines. North American calls for guidelines to recognise quality IS research (King 1993) must be even more pertinent in Australia where IS researchers have additional pressures of diverse work histories and educational backgrounds (Shanks, Rouse \& Arnott 1993). Partly as a consequence, Australian IS research traditions have yet to be established and gain recognition (Ridley 1996). Culnan (1987) urged the monitoring of the 'state of development [of IS] on an ongoing basis'. This paper is one attempt to monitor those aspects of the development of mainstream IS research traditions in Australia that relate to the contribution of institutions, departments, authors and collaboration to the IS research profile.

The research reported below is part of a larger study that investigates the nature and development of IS research in Australian universities. One phase is an analysis of the publication patterns of Australian IS researchers. If publication is a 'legitimator of academic performance' (King 1993), then it is important for the greater status of IS research and consequent improved access to resources that Australian IS publication patterns be known (Ridley 1996). As resources are usually allocated on a national or more local level, for example Australian Research Council grants and general university funding, traditions of IS research need to be established at a national level, not only at an international level.

Despite a body of literature emanating from North America that has investigated the contribution of institutions and authors to the IS research profile, little work of this kind has been conducted in Australia. However, research of such a nature is timely now that an awareness of a need for a political presence is developing in Australian IS, as demonstrated by the formation of potential lobby groups such as the IS Heads of Discipline meetings (Ridley 1996). One example of such research conducted at the individual department level is reported in a paper by Cue and Urquhart (unpub. 1997) that benchmarks the research output of one Australian IS department against that of others. However, as far as the authors are aware, a specific analysis of Australian IS academic research has not been published.

Such an analysis will provide useful information for staff and postgraduate students seeking a place in Australian IS, for benchmarking within a department or school (hereafter stated only as department), institution or the discipline and for the allocation of resources. Changing patterns of research collaboration will track growth in a shared understanding of the nature of Australian IS research, and over time will have the potential to trace progress in the development of the IS scientific community. Such data must also provide fundamental

${ }^{10}$ A previous version of this paper was presented at the 8th Australasian Conference on Information Systems, 1997, and appeared in the proceedings of that conference. 
background information for people striving to improve the status and power of Australian IS research (Ridley 1996).

The aim of this paper is to report on an investigation of the contribution and collaboration of institutions, departments and authors to mainstream IS research published in Australia over the period 1990 to 1996 , and to study some characteristics of the authors. It seems reasonable to examine Australian IS mainstream publication outlets in order to investigate Australian IS mainstream research. It is acknowledged however that some IS researchers will have submitted papers to specialist publication outlets in addition to mainstream IS outlets. Other Australian IS researchers will have targeted mainly international publication outlets.

There are only two Australian refereed outlets that publish papers at least annually and cover a broad range of IS themes and methodologies. The first is the Australasian Conference on Information Systems (ACIS) and the second is the Australian Journal of Information Systems (AIS). Moreover, AJIS and ACIS are the two leading Australian publication outlets considered to be appropriate for the dissemination of Australian IS research (Ridley 1996). ACIS proceedings and AIS have been analysed from the first issue until the end of 1996. The analysis period commences in 1990 as it was the first year that ACIS was held.

\section{BACKGROUND}

\section{Journals as machines of control}

Many authors have argued a need for IS researchers to work less independently, develop underlying theories for the discipline (Farhoomand 1987) and for individual researchers to build on the work of others (Keen 1980). 'Fact construction' is a collective process needing the support of a network or scientific community of researchers, a process that cannot be achieved by isolated researchers (Latour 1987). Latour stated that with the assistance of a 'machine', which can be either a physical mechanism or a less tangible 'stratagem' such as an organisational system, it is possible to unite researchers to form a scientific community.

Walsham (1995) built on Latour's ideas in his application of them to the discipline of IS, and considered IS journals to be 'machines or stratagems for enrollment [sic] and control'. He considered that journal editors enlisted both the editorial board and referees to control the scope, epistemology and research strategies of papers from prospective contributors to the journal. If Walsham is correct, over time in the history of a publication outlet, there will arise certain institutions, departments, authors and employment sectors that are favoured through repeated publication because the scope and nature of their research represents quality research from the perspective of the editorial board and referees, which will encourage further submissions.

AJIS and ACIS proceedings are the only two at least annual general IS academic publication outlets in Australia. Therefore it is argued that institutions, departments and authors that repeatedly publish in the two outlets will be mainstream members of the Australian IS scientific community and growth in their numbers will represent growth in that community. Furthermore, the nature of the papers will constitute many of the 'research traditions' of that community. Patterns of collaboration will trace growth and links of the Australian IS scientific community between and among universities, departments, researchers, IS practitioners and academia and between Australia and other nations. Developments in these links will reveal changes to the degree of isolation of individual researchers and the development of the Australian IS scientific community itself from a number of individuals to a network of researchers, able to undertake 'fact construction'.

Perhaps it is in the early stages of the development of a discipline that journals (and refereed conferences) are most useful as a means of communicating and instructing neophyte and potential members of a scientific community in the group research traditions. Once the discipline is established, it appears that other journals emerge to represent non-mainstream groups. For example, in the international IS community, positivist papers such as those commonly found in MIS Quarterly (first published in 1977) typified mainstream research (Walsham 1995), but more recently other, often European 'nontraditional' IS journals were introduced that published interpretivist papers (Orlikowski and Baroudi 1991; Walsham 1995). Examples of 'nontraditional' IS journals include the European Journal of Information Systems and Accounting, Management and Information Technologies (both first published in 1991). After a discipline has been established for some time the strong unifying influence of a traditional journal is challenged by 'stratagems' other than non-mainstream journals. These include a uniform discipline-specific educational programme for prospective researchers, national electronic mailing lists, the strong bonding influences of research groups within a department and networks of 'invisible colleges' that link researchers in different departments, universities and nations to common topics, epistemologies, research methods and approaches.

IS has been established in North America for a considerable time. As stated earlier MIS Quarterly was first published in the United States of America in 1977 where the first ICIS conference was also held in 1980 . The influence of North America is powerful and prevails upon Australian IS researchers. The prestigious North American journals and conferences are regarded as mainstream publication outlets in Australia, and are 
considered appropriate for the publication of Australian IS research results (Ridley 1996). However, despite this influence the authors suspect that Australian IS research has a distinctive style which is different to that carried out in North America. If there is an Australian flavoured IS research, then at least some IS research traditions in Australia are likely to differ in nature to those held elsewhere.

In Australia, the local perspective of appropriate and quality IS research traditions have been represented and engendered by ACIS since 1990 and AJS since 1993. It is only in 1997 that the influence of ACIS and AJIS to 'control' the research traditions of Australian IS researchers has been challenged with the planned introduction of The Journal of Holistic Research in Information Systems. The aims of the journal are stated as fostering '...primarily interpretive or qualitative research methods...' (Standing 1996).

\section{Invisible Colleges}

De Solla Price (1961, 1963) first described the 'invisible college'. Culnan (1987) defined 'invisible colleges' as the clustering of researchers into informal networks 'which tend to concentrate on examining common questions in common ways'. De Solla Price (1963) described how invisible colleges diffuse knowledge through collaboration. Therefore, patterns of collaboration will help identify invisible colleges. De Solla Price saw some practices of invisible colleges as threatening the role of journals, and gave as an example the distribution of prepublication papers to members of an invisible college (1961; 1963). The use of electronic mailing lists for this purpose exemplifies the threat de Solla Price foresaw 25 years ago. De Solla Price's concern suggests there is a time sequence in the development of a scientific community, with the setting up of mainstream journals belonging to an earlier phase than the operation of resilient invisible colleges. He saw membership of an invisible college as conferring power and status on an individual and the network (1963). It is these networks of researchers that are best placed to lobby for better access to resources and funds (Ridley 1996).

For collaboration to be possible, researchers must have a common understanding that their research scope is valued and agree on the philosophical approach and research strategies to be employed. Therefore it is through collaboration that traditions of research are established and disseminated, to make invisible colleges a powerful 'stratagem' to initiate and nurture researchers into the norms and mores of a research community.

Although several North American papers have investigated the research profile of IS institutions, departments and authors, few, if any, considered the contribution of Australian research. As a result there is no means of comparing Australian researchers. An overview of the relevant North American literature is now presented. Emphasis is placed on the methodology of the studies, in addition to the results.

\section{Literature on research profiles of institutions, departments and authors}

Joint authorship of papers is commonly found in IS journals and conference papers. Lindsey (1980) examined three different approaches to calculate the contribution of an individual author where joint authorship exists.

The first is the 'normal count', where an equal unit count is ascribed to each joint author. In the 'adjusted count' one joint author is attributed with a fraction of a unit count which will decrease as the number of authors increases. The 'straight count' attributes the paper solely to the first listed author so that co-authors receive no credit. However the straight count is seen as inequitable to co-authors other than the first listed. The adjusted count is viewed by Lindsey as more just, but it is hard to maintain. As the normal count is the most usual method used to attribute credit to multiple authors (Lindsey 1980) it has been used in this study.

Jackson and Nath (1989) examined the publication patterns of Management Information Systems (MIS or IS) researchers over the period 1975-1987. They analysed 899 papers from ten well known North American journals to find that the leading 32 researchers contributed 18 percent of the total research examined and that a majority of the leading IS researchers were located at a few schools. The study found that 47 percent of the papers had one author, 41 percent had two authors, ten percent had three authors and two percent had four or more authors and that there had been an increase in the number of institutions with leading researchers. Jackson and Nath (1989) calculated credit for joint authorship using all three methods in turn, but referred to the normal count findings in their conclusion.

Grover, Segars and Simon (1992) weighted IS article contributions over the period 1982-1991 in three timeslices from five leading journals using 'standardized pages' and an adjusted count. The papers were credited to over 190 institutions which were then ranked. Following the recommendation of Niemi (1987) the authors made no adjustment for department size. They found that the top fifteen institutions contributed over half the research examined. Between 1982-86 and 1987-91 the IS research output of the journals increased by 97 percent. Grover, Segars and Simon allotted credit to institutions based on the affiliations listed on the papers even though they may have changed since publication.

Lending and Wetherbe (1992) and Vogel and Wetherbe (1984) used an adjusted count to produce a profile of leading universities by identifying 389 and 744 IS papers in 15 and 13 leading journals respectively. They found 
that both the quantity of papers and the number of universities had almost doubled between 1977-1983 and 1984-1990. In the 1992 study the authors concluded that even though ten percent of the MIS schools produced 44 percent of the total published research there was less domination by the most productive schools.

Shim, English and Yoon (1991) determined the 60 most frequently published IS authors from 817 papers in a weighted group of eight leading IS journals for the years 1980-1988 using an adjusted count. They found that each of the sixty authors had a minimum of four papers.

\section{METHODOLOGY}

\section{Epistemology, research question and methods}

The study was carried out within a descriptive, positivist framework (Orlikowski \& Baroudi 1991). The aim of the paper was to report on an investigation of the contribution and collaboration of institutions, departments and authors to non-specialist IS research published in Australia during 1990-1996 inclusive, and to study some characteristics of the authors. Space limitations prevent the reporting of an analysis of IS papers by Australian authors published elsewhere. Descriptive statistical analysis was employed.

\section{Sources of data}

Other than ACIS, general IS conferences are only occasionally held in Australia, for example the Pacific Asia Conference on Information Systems and the TC8AUS IFIP Information Systems International Working Conference. Even though the Australian Computer Journal publishes a mix of IS and Computer Science papers, the number of IS papers is low, whereas in AIIS all papers are from IS. Although eminent Australian IS researchers do publish in general refereed IS international journals and conference proceedings, the total number of such papers is very small. Specialised publication outlets were excluded for the reasons previously stated. Apart from ACIS and AIS there is no other general publication outlet which publishes Australian IS research papers both frequently and regularly.

The ACIS proceedings derive from a conference while AJIS is a journal. As the combined number of papers is sizeable, an analysis of the papers should be representative of generalist refereed IS research published by Australians. Both ACIS and AIS were perceived by influential Australian IS researchers as belonging to the third of three tiers of IS publication outlets considered appropriate for the publication of Australian IS research when ranked by quality (Ridley 1996). However, very few Australian published papers are found within publication outlets from the first and second tiers.

ACIS has been held annually since its inception in 1990. It is regarded as the 'focal meeting point for IS researchers in Australasia' (Sutton 1997). The first two conferences were run in association with the Australian Conference on Computer Science (Arnott unpub. 1995), but from 1992 the conferences were held independently. In 1990 the ACIS proceedings contained fifteen papers while in 1996 there were 72 refereed papers in 846 pages. AJIS is a biannual journal first published by the Department of Business Systems at the University of Wollongong in 1993. It publishes papers that relate to the theory and practice of Information Systems. It has published from six to nine papers per issue and regularly publishes papers from both Australian IS researchers and those from outside Australia.

\section{Procedure and analysis}

All refereed papers from all editions of AJIS and ACIS for the inclusive period 1990-1996 were analysed. Although the institution and department names were recorded from affiliations stated on the papers, some institutions and departments have restructured while some authors have changed their institution or organisation since their paper was published. Where the department of one of joint authors was given but not the institution it was assumed that the institution was the same as for the other author/s. Where two affiliations were given for an author, only the first was recorded on the assumption it was the major one. When only a private address was given for an author it was assumed that he or she was a practitioner (or ex-student). Post-graduate students were recorded in the academic count. As AIS volumes run across calendar years, to be consistent with the ACIS counts calendar years were used for the AJS figures rather than volumes. The paper was used as the unit of measurement. As percentages were rounded to the nearest whole number, totals may exceed one hundred percent.

A frequency count of Australian academic institutional and departmental affiliations of authors was made. If a research centre was associated with a department, the department name was used. Then a frequency count of academic and practitioner Australian authors was performed. 
This study regarded collaboration as the publishing of joint research resulting from the co-operation of researchers in different institutions. To investigate the nature of author collaboration, firstly the number of authors was recorded for those papers authored by Australian practitioner and academic authors. Where papers were jointly authored by at least one author in Australia and one outside Australia, those papers were included. Secondly, analysis was conducted of all jointly authored papers with at least one Australian author by the employment status and location of the authors, that is whether collaboration took place within the same department of an Australian university or organisation, within different departments of the same Australian university, different universities within Australia, between universities within and outside Australia, between Australian academics and practitioners or between academics and practitioners where at least one came from Australia and at least another from outside Australia.

Then an analysis was undertaken to investigate some characteristics of authors. Frequencies of the employment status and geographic location of Australian university author/s were recorded.

\section{RESULTS AND DISCUSSION}

A total of 382 papers were examined, of which 50 were from AJIS and the rest from ACIS.

\section{Most published universities}

Table 1 lists the seven most published universities with 24 or more IS refereed papers in ACIS and AJIS during 1990-1996. The cut-off point was chosen at the 81st percentile (of universities) after the seventh where a break from 24 to 16 papers occurred. The group of seven made up only 19 percent of the 36 universities that published papers, yet accounted for 61 percent of the 496 total author credits for Australian academic papers. As the normal count was used, each entry may record the sole contribution of an author to a paper, or a co-author contribution, which may have been in conjunction with another university. The figure for the University of New South Wales included the papers for the Australian Defence Force Academy.

\begin{tabular}{|c|c|c|c|c|c|c|c|c|c|c|c|c|c|c|c|}
\hline \multirow[t]{2}{*}{ University } & \multicolumn{2}{|l|}{ '90 } & \multicolumn{2}{|l|}{91} & \multicolumn{2}{|l|}{ '92 } & \multicolumn{2}{|l|}{ '93 } & \multicolumn{2}{|l|}{94} & \multicolumn{2}{|l|}{95} & \multicolumn{2}{|l|}{ '96 } & $\begin{array}{l}\text { TOTAL } \\
\text { S }\end{array}$ \\
\hline & $\begin{array}{l}\mathrm{ACI} \\
\mathrm{S}\end{array}$ & AJS & $\left|\begin{array}{l}A C I \\
S\end{array}\right|$ & AIS & $\begin{array}{l}\mathrm{ACI} \\
\mathrm{S}\end{array}$ & AJS & $\begin{array}{l}\mathrm{ACI} \\
\mathrm{S}\end{array}$ & AIIS & \begin{tabular}{|l} 
ACI \\
$\mathrm{S}$
\end{tabular} & AIIS & $\begin{array}{l}A C I \\
S\end{array}$ & AЛS & $\begin{array}{l}\text { ACI } \\
S\end{array}$ & AлIS & \\
\hline Curtin & & & 1 & 38 & & & 9 & & 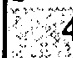 & & 8 & & 4 & & 36 \\
\hline Monash & 2 & & 2 & 2 & 4 & (t) & 89 & & 38 & & 22 & 2 & 11 & 2 & 90 \\
\hline Swinburne & & 1. & 1 & fym & 3 & 8 & 8 & & $\because 6$ & 3 & 15 & 3 & 5 & 4 & 45 \\
\hline U of Melbourne & 2 & 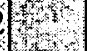 & 2 & 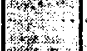 & 2 & & 1 & & 3 & & 6 & 2 & 6 & 1 & 24 \\
\hline U of NSW & 5 & 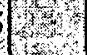 & 3 & 7 & 3 & 40 & 5 & 6 & 8 & & 3 & & 3 & & 35 \\
\hline $\mathrm{U}$ of Tasmania & $\ldots$ & to & 准 & Ho & 3 & $\ldots$ & 1 & & 6 & & 6 & & 12 & 1 & 26 \\
\hline $\begin{array}{l}\text { U of } \\
\text { Wollongong }\end{array}$ & & 4 & 1 & 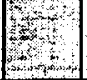 & 11 & 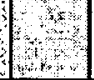 & 2 & 1 & $t$ & & 6 & 2 & 3 & 1 & 33 \\
\hline TOTALS & 10 & 0 & 10 & 00 & 26 & 20 & 35 & 7 & 69 & 4 & 766 & 9 & 44 & 9 & 289 \\
\hline
\end{tabular}

Table 1 Most Published Universities

A correlation between the university hosting ACIS and the number of papers published in that year was noted, a likely consequence of the increased consciousness and enthusiasm that hosting the conference generated in the host university.

There were 36 Australian universities that participated in the IS research community in Australia and were willing to conform to the research scope, methodology and methods considered relevant and rigorous by AJIS and ACIS. A core group of seven universities assumed a leading role in the establishment of Australian research traditions.

\section{Most published departments}

There were 96 departments from which an author had published a paper in AIS or ACIS. Table 2 lists the four most published Australian university departments with 22 or more IS refereed papers published in ACIS and AJIS during 1990-1996. The cutoff point was chosen after the four most published departments despite the belief by the authors that a larger listing would have been of interest to the Australian IS community. However, a large break from 22 to 14 papers was apparent after these departments, the fourth of which was on the 96th percentile (of departments), and no break with more than a difference of one occurred at any other place in the 
table. To have made the cutoff point at any other point in the table would have resulted in choosing the most published departments in an arbitrary manner. The four departments authored around 29 percent of the 496 total author credits for papers from Australian departments. Any entry in Table 2 may record the sole contribution of an author to a paper, or a shared contribution with another department where there were multiple authors. The percentage of the total papers published by each of the four most published departments was considerably less than the percentage of the total papers published by their universities as many universities had more than one department where IS research was undertaken. The departments that were not the most published and yet belonged to one of the 'most published universities' may have included authors who published in AIS and ACIS and identified with the IS community. However, the departments may also have included other authors who did not identify with general IS but who found it expedient to publish in IS publication outlets, or who identified with IS as well as some other or more specialised discipline or field.

\begin{tabular}{|c|c|c|c|c|c|c|c|c|c|c|c|c|c|c|c|}
\hline Department & 90 & 6 & 91 & 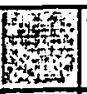 & 92 & 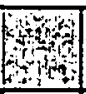 & 993 & & 94 & & 995 & & .96 & & $\begin{array}{l}\text { TOTAL } \\
\text { S } \\
\end{array}$ \\
\hline & \begin{tabular}{|l|}
$\mathrm{ACl}$ \\
$\mathrm{S}$
\end{tabular} & AIS & \begin{tabular}{|l|}
$\mathrm{ACI}$ \\
$\mathrm{S}$
\end{tabular} & AगS & $\begin{array}{l}\mathrm{ACI} \\
\mathrm{S}\end{array}$ & AЛS & \begin{tabular}{|l|}
$\mathrm{ACI}$ \\
$\mathrm{S}$
\end{tabular} & AIS & $\begin{array}{l}\mathrm{ACI} \\
\mathrm{S}\end{array}$ & AIIS & $\begin{array}{l}\mathrm{ACI} \\
\mathrm{S}\end{array}$ & AIIS & \begin{tabular}{|l}
$\mathrm{ACI}$ \\
$\mathrm{S}$
\end{tabular} & AIIS & \\
\hline $\begin{array}{l}\text { Curtin } \\
\text { School of IS }\end{array}$ & & 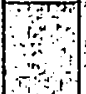 & & कat & $\because 6$ & 4 & 6 & & 4 & 1 & 7 & & 3 & & $\begin{array}{r}0 \\
27\end{array}$ \\
\hline $\begin{array}{l}\text { Monash } \\
\text { Dept of IS }\end{array}$ & 2 & 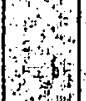 & 2 & bet & 2 & of & 5 & & 28 & & 17 & 2 & 4 & 1 & 61 \\
\hline Swinburne & 20 & Pat & m & 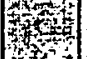 & 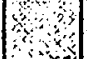 & 2 & & & $\%$ & & & & & & 0 \\
\hline $\begin{array}{l}\text { School of IS } \\
\text { U Or NSW } \\
\text { School of IS }\end{array}$ & क & 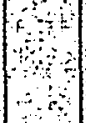 & 1 & 4 & $\begin{array}{r}21 \\
3 \\
3\end{array}$ & 4 & $\begin{array}{r}2 \\
2\end{array}$ & & 83 & & 12 & 1 & 2 & 4 & $\begin{array}{r}26 \\
0 \\
2 ?\end{array}$ \\
\hline TOTALS & 6 & 0 & 6 & sing & 12 & 0 & 13 & 4 & 40 & 1 & 38 & 3 & 10 & 5 & 136 \\
\hline
\end{tabular}

Table 2 Most Published Departments

The findings indicated that there were 96 Australian departments that participated to varying degrees in the general Australian IS research community and had been willing to comply with the scope, methodology and research methods viewed as acceptable by AJIS and ACIS. Of this large group there was a primary group of four departments that had taken a leading role in the establishment of research traditions in Australia. These four were considered to be leading departments because of their publication activity.

In the previous two tables, it is interesting to consider the period over which the individual universities and departments published their papers. In some instances the publications were achieved over the full seven year period, while in others, in fewer years. In general, however, it was from 1993 that the number of publications increased.

\section{Most published authors}

A total of 314 Australian authors had published in one, either or both of the two outlets.

Table 3 gives the number of authors with one, two, three and four or more papers published in AIIS and ACIS. It can be seen that there was a cohort of 20 Australian academic or practitioner authors with four or more refereed papers published during 1990-1996. The cohort cutoff point at the 94th percentile (of authors) excluded those authors who had published three papers. Members of the most published author cohort were listed as authors in 105 of the $\mathbf{4 9 6}$ author credits from the 382 papers, and made up more than 21 percent of the total author credits. Each paper may represent either a solely or jointly authored paper.

\begin{tabular}{|c|c|}
\hline No. of Papers & No. of Authors \\
\hline $4+$ & 20 \\
3 & 22 \\
2 & 53 \\
1 & 219 \\
\hline
\end{tabular}

Table 3 Number of Authors with Four or More, Three, Two or One Published Papers

It is interesting to note that the seven most published universities employed fifteen of the most published authors, while the four most published departments employed twelve. The calculations were based on the affiliation given in the authors' latest publication. The figures demonstrate that the centres of influence in Australian IS research had a narrow base. 
If publishing a refereed paper in one of the two publication outlets during the period is regarded to be the criterion for membership, it can be seen that at the end of 1996 there were 314 people in Australia who could be considered to belong to the general IS research community, in addition to the handful of eminent researchers who published internationally. However, some of the 314 researchers were likely to identify more strongly with another research community. IS intersects with many disciplines, and it may be expedient for researchers from an allied discipline to publish in an IS outlet. Members of this group were most likely to be found in the group who published just once.

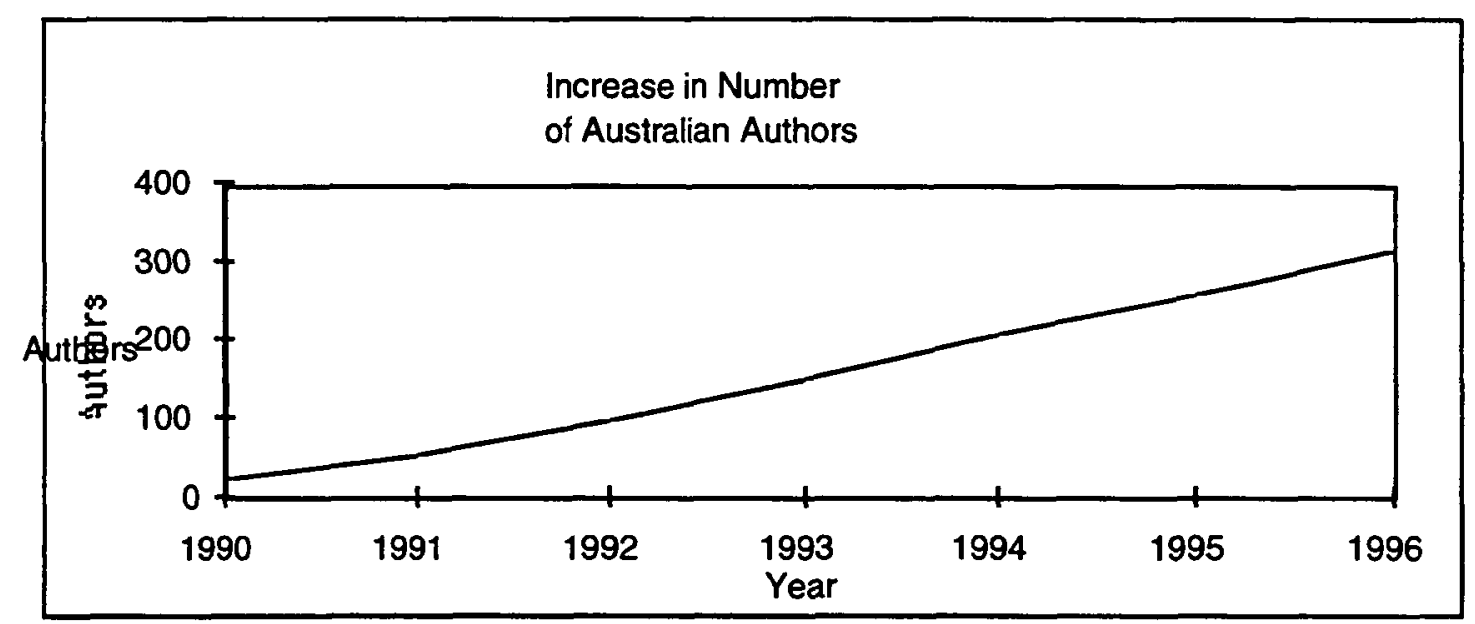

Figure 1 Cumulative Total of Published Authors, ACIS and AJIS Combined

As can be seen in Figure 1 above, there has been a steady growth in the combined ACIS and AJIS cumulative total of Australian authors over the period 1990-1996, which indicates in turn growth in the Australian IS research community.

\section{Collaboration}

Figure 2 and Table 4 investigate the nature of collaboration during the period 1990-1996.

Figure 2 presents the combined yearly totals of ACIS and AIIS Australian practitioner and academic papers by the number of authors. Non-Australian authors were included where a paper was written in collaboration with an Australian author. It was found that 143 of the 307 total papers under consideration, or 47 percent were written by one author, 119 or 39 percent were written by two authors, 34 or eleven percent were written by three authors while eleven or four percent of the papers were written by four or more authors. Over the period more than half of the papers were written collaboratively which suggests that in general, Australian IS researchers did not research independently but undertook research with others, most commonly with one other. After 1993 there was a decline in the number of papers written by one author and an increase in the number of collaborative papers. The data suggests that invisible colleges were established in Australian IS research from around 1993.

Note that non-Australian authors were included where they co-authored with an Australian.

Collaboration leads to the articulation and sharing of research traditions and the eventual development of invisible colleges. The most obvious way that collaboration encourages shared research traditions is through the supervisor/research student relationship, and it is likely that many of the collaborative links observed have arisen in this manner. When a research student graduated and found work elsewhere in academia the invisible college was extended. However where a university's policy towards the allocation of Department of Employment, Education, Training and Youth Affairs publication points is to use the 'straight' or 'adjusted count' and so not give full credit to all authors, this will act to limit cross-departmental and intervarsity collaboration. Having established that collaboration is common and invisible colleges are likely, it is interesting to contemplate where the collaboration has taken place. 


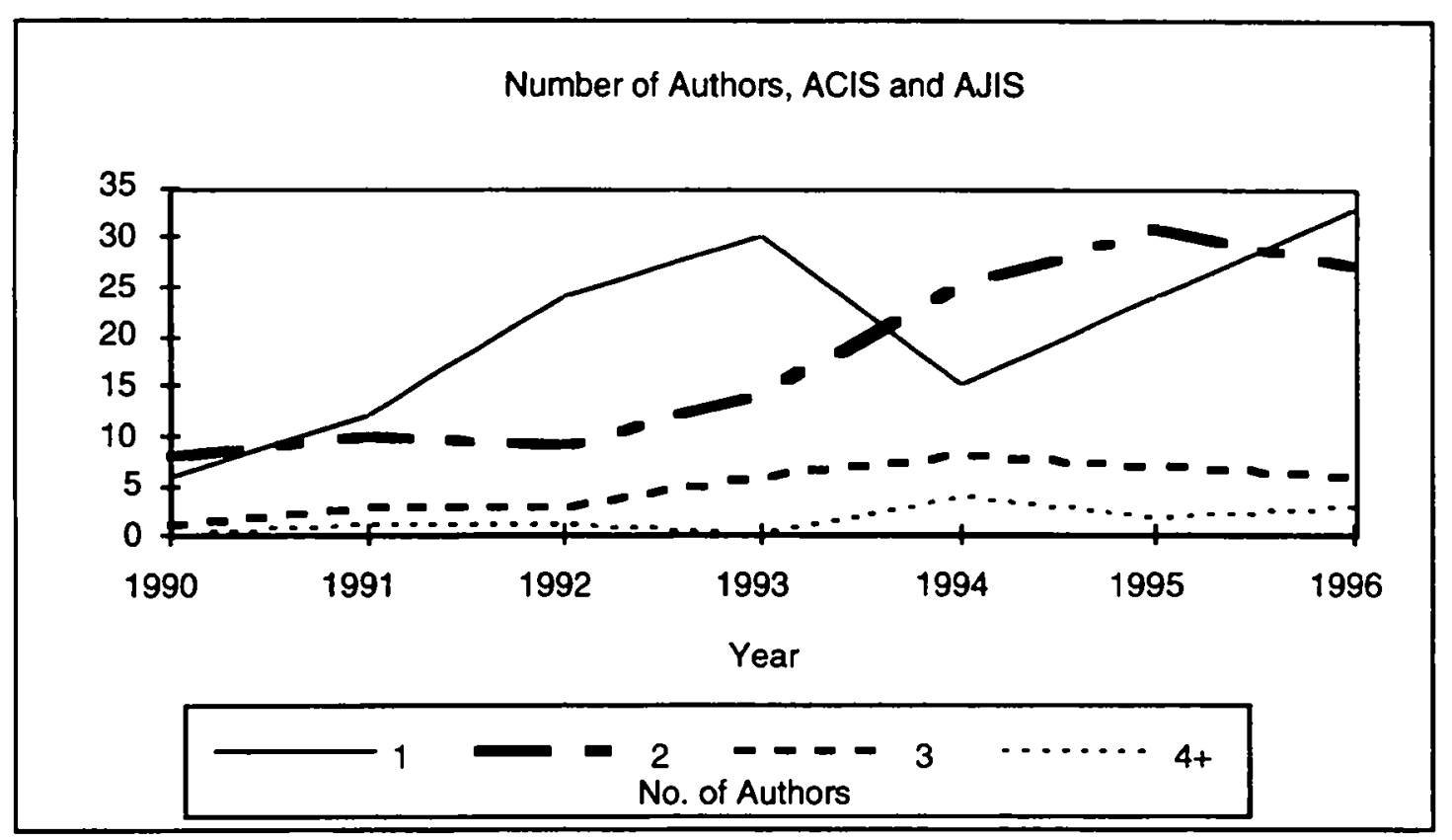

Figure 2 Graph of Number of Authors in ACIS and AIS Australian Papers

Table 4 analyses ACIS and AIS Australian papers by author collaboration. In this table one paper may be recorded within several categories where there were greater than two authors. Only jointly authored papers with at least one Australian author were recorded. It can be seen that 101 of a total of 174 papers recorded in this way, or 58 percent were written collaboratively where the authors came from within the same department of the same university. Although departments differ in their policy regarding the addition of a supervisor's name to papers written by research students, it is likely that some of these papers were co-authored by research student/supervisor groups. It is possible that some papers jointly authored by a supervisor and research student where the student was employed as an academic at another department or institution may have stated the affiliation of the student as that of the supervisor. However, such an under-estimation of intervarsity collaboration may have been balanced by other papers. For example, some papers written under the guidance of a supervisor may have given only the student's name and affiliation.

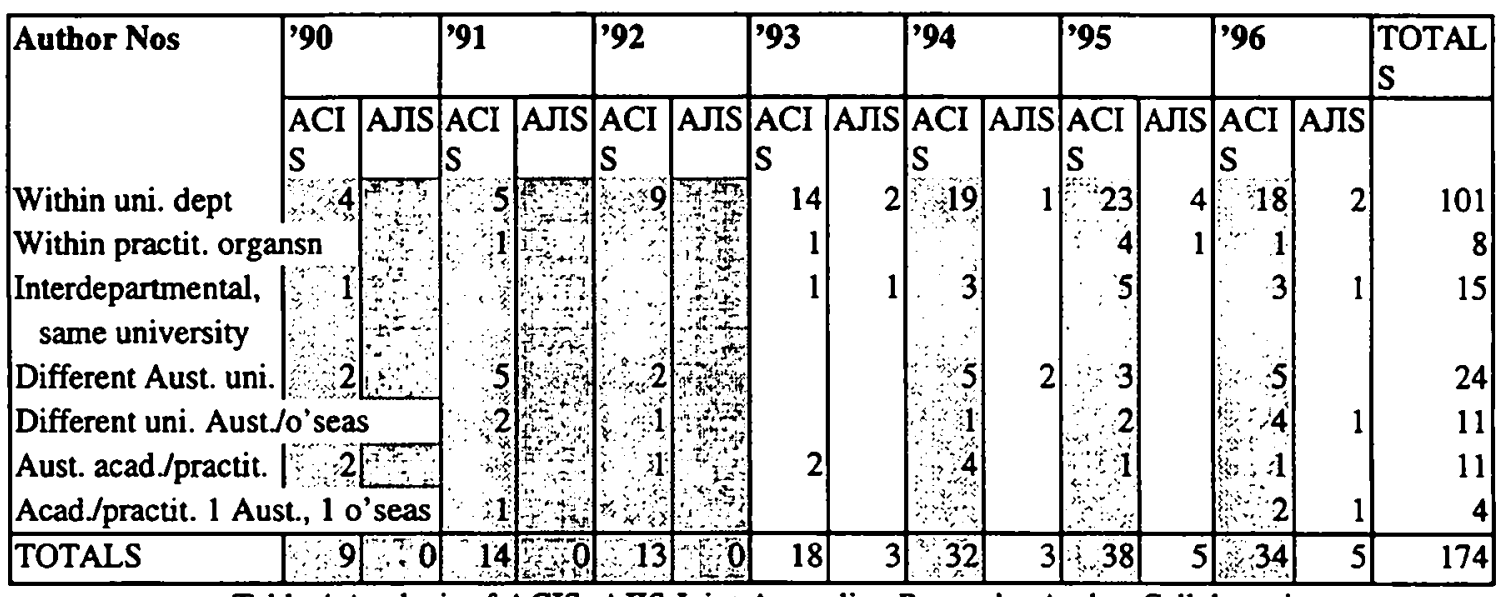

Table 4 Analysis of ACIS, AJS Joint Australian Papers by Author Collaboration

Only eight of the 174 papers, or five percent were collaborative practitioner papers and in fifteen of the 174 papers, or nine percent, authors collaborated within different departments of the same university. Just 24 of the collaborative papers or fourteen percent were written by authors from different universities within Australia. Collaboration between different universities in Australia and outside Australia, and joint academic/practitioner papers where both parties came from within Australia each accounted for eleven of the papers, or six percent. Finally, four of the 174 papers or two percent were written jointly by academics and practitioners where one came from Australia and the other from outside Australia. 
The data demonstrated that collaboration between colleagues in the same department of a university was more than four times as common as any other form of collaboration. This finding suggests that in addition to researchers working independently, they also worked in independent departmental units. Moreover, over twice as much collaboration occurred between researchers in different universities than between different departments of the same university. This is remarkable given that, (a) the broad scope of IS and the influence of many different reference disciplines offer considerable potential for interdisciplinary research, and (b) the finding discussed earlier that many universities had several departments where IS research took place, yet little shared research occurred between them. If IS research methods borrowed heavily on those from other disciplines such as computer science, management and sociology, they did so in Australia without a great deal of interaction taking place with those disciplines. This finding has implications for both the quality of the research produced and the likelihood of researchers gaining access to grant funds. However, it is likely that the sizeable collaboration that has occurred between researchers in different universities within Australia and outside Australia has contributed to the development of a shared understanding of research traditions, and is evidence of invisible colleges.

The data displayed patterns of collaboration between academics and practitioners. In general little collaboration took place between academics and practitioners despite the applied nature of IS. It is interesting to note that there was more research published that resulted from collaboration between academics and practitioners than was published by practitioners. Practitioners may have felt that the publication outlets were not appropriate forums. Whatever the cause, it indicates a divide between the practitioner and academic IS world in Australia.

Comparison was made between the findings of this study and that of North American research. It was remarkable to observe that the proportions of Australian papers with one, two, three or four or more authors were almost identical to those reported in a North American study (Jackson and Nath 1989). In the same study the 32 most prolific researchers authored 18 percent of the total research whereas in the Australian study twenty researchers accounted for 21 percent of the total number of author credits. Following a similar pattern, Grover, Segars and Simon (1992) found that the fifteen most prolific universities authored over half the research examined, while Lending and Wetherbe (1992) reported that the most prolific five MIS institutions accounted for eighteen percent of the published research. In comparison, in the Australian study, the most prolific seven universities were responsible for 61 percent of the total author credits. It is worth noting that in general the North American studies made no differentiation between leading institutions and schools as MIS academic research is commonly based in one school within each institution whereas in Australia the current study found that IS research is often undertaken within several departments of the one university. As a result although it was found that in Australia the most prolific four percent of departments accounted for 29 percent of the total author credits there is no meaningful North American comparison.

Even though measurement has been made in different ways, in the comparisons made the most prolific universities and authors in Australia accounted for either an absolute or suggested greater proportion of the IS research output than was reported in North America. This finding and the finding that IS research in North American universities tended to be based in one centre are indicative that at least some characteristics of Australian IS research are different to those in North America. It was reported in two comparative studies (Lending \& Wetherbe 1992; Vogel \& Wetherbe 1984) that there was less domination by the most prolific schools in the later study. From this finding it is surmised that the earlier in the establishment of an IS scientific community, the greater the domination of the research output by a few universities, departments and authors. The Australian findings are consistent with this, as Australia clearly is at an earlier stage of development of its IS scientific community. It is expected that over time, the leading universities, departments and authors will reduce their domination of the published research output in Australia as the scientific community grows.

All refereed authors published by ACIS and AJIS during 1990-1996 were analysed by their employment category and whether they were from within Australia. Table 5 gives a breakdown of authors of refereed papers from AJIS and ACIS by their employment group and geographic location. Each paper appears only once.

It can be seen from Table 5 that 261 of the total of 382 papers analysed came from Australian academic authors. This was over four times as large as any other group and represents 68 percent of the total. There was only one other sizeable group. A total of 61 or sixteen percent of the papers were written by academics with affiliations from outside Australia. This means that academic authors dominated the publication outlets.

Only six percent of papers were written by practitioners and seven percent of the papers were written by practitioners in collaboration with academics. The analysis of the characteristics of all the practitioner papers in the two publication outlets corroborates the findings of the prior analysis that focussed on the pattern of collaboration in joint papers. There was only limited evidence of interaction between academic and practitioner researchers in the Australian publication outlets, either from the exposure of academics to practitioner papers or in joint papers. This was particularly so when the practitioner or joint practitioner/academic papers from outside Australia were excluded. 
Author characteristics

\begin{tabular}{|c|c|c|c|c|c|c|c|c|c|c|c|c|c|c|c|}
\hline Author & 90 & & '91 & & '92 & & 93 & & '94 & & '95 & & '96 & & $\begin{array}{l}\text { TOTAL } \\
S\end{array}$ \\
\hline Characteristics & $\begin{array}{l}\mathrm{ACI} \\
\mathrm{S}\end{array}$ & AJIS & $\begin{array}{l}A C I \\
S\end{array}$ & AJIS & $\begin{array}{l}\mathrm{ACI} \\
\mathrm{S}\end{array}$ & AJIS & $\begin{array}{l}A C I \\
S\end{array}$ & AJIS & $\begin{array}{l}\mathrm{ACI} \\
\mathrm{S}\end{array}$ & AЛS & $\begin{array}{l}\mathrm{ACI} \\
\mathrm{S}\end{array}$ & AJIS & $\mid \mathrm{ACI}$ & AJIS & \\
\hline Aust academics & 13 & mats & 22 & 18 & 28 & 4 & 41 & 5 & 39 & 6 & 41 & 9 & 52 & 5 & 261 \\
\hline Aust practitioners & & 4 & & 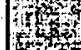 & & Hes & 1 & & 2 & & 2 & 1 & 6 & & 14 \\
\hline Aust acad/practit & 2 & mat & & 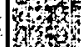 & & Xin & 2 & & 4 & & 3 & & & & 19 \\
\hline O'seas academics & & W & & 4 & 9 & pots & 14 & 2 & 7 & 4 & 7 & 3 & $a \quad 4$ & 9 & 61 \\
\hline $\begin{array}{l}\text { O'seas } \\
\text { practitioners }\end{array}$ & & (5) & & 37 & & ont & 1 & 1 & 3 & & 2 & & & 1 & 8 \\
\hline O'seas acad/practit & & 3 & & thes & & 6n & 1 & & & 2 & 0 & & & & 6 \\
\hline Aust/o'seas academi & & por & & $4 y^{2}$ & 1 & Hey & & & 1 & & 1 & & $\because 4$ & 1 & 10 \\
\hline Aust/o'seas practitio & oners & 4 & & 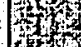 & & fon & & & & & & & & & 0 \\
\hline Aust/o'seas acad/pra & actitic & ners & & Matan & $\sqrt{8}$ & 10 & 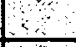 & & & & & & 1 & 1 & 3 \\
\hline TOTALS & 15 & 190 & 28 & the & 39 & 80 & 60 & 8 & 56 & 12 & 56 & 13 & 378 & 17 & 382 \\
\hline
\end{tabular}

Table 5 Analysis of ACIS, AJIS Papers by Author Characteristics

Papers jointly authored by academics from Australia and outside Australia accounted for ten papers, or only three percent of the total published papers. This result indicates that little general IS collaborative research between Australian academics and academics from outside Australia was published in Australia. This may be a result of little research of this nature being undertaken, or it could be that the collaborative authors preferred to publish their work in international journals as those journals have more prestige. As beguiling as the second possibility seems, it is considered unlikely as very few collaborative papers of this nature were found in leading international journals by one of the authors in work carried out for another purpose. Even when the small group of eminent authors who publish in international rather than national outlets is remembered, there are few general IS research invisible colleges that reach out from Australia to researchers elsewhere.

\section{LIMITATIONS; RECOMMENDATIONS FOR FUTURE RESEARCH}

An obvious limitation of the study is the restricted number of publication outlets used for the source of the data. A related limitation is the exclusion of specialised conferences and journals. As has been noted, a very small number of eminent Australian IS researchers identified most closely with the international IS scientific community, published in international journals and participated in international conferences. These authors have been missed by the current study which examined Australian publication outlets only. It can also be seen that use of the normal count method will give rise to different results than if use was made of the adjusted or straight count.

Further investigation will need to determine whether Australian specialist IS publication outlets are similar to the two mainstream outlets for the characteristics examined in the current study. The next step will be to identify the research traditions in use by the IS academic community. It will be possible to specify the research scope, methodology and methods used by the Australian mainstream IS research community by analysing ACIS and AJIS papers for these characteristics. This task is currently being undertaken by the authors.

\section{CONCLUSIONS}

The authors who published in AIS and ACIS were willing to comply with the research traditions considered acceptable by AIS and ACIS, and these publication outlets are largely shaping the research traditions of the Australian mainstream IS scientific community.

If at least one publication of a paper by an Australian academic or practitioner in one of the two publication outlets is taken to be the criterion of membership of the Australian mainstream IS research community, it was found that the community comprised of around 36 universities, 96 departments and 314 authors. It needs to be remembered however, that some of these universities and departments do not currently exist in the same form. Seven universities, four departments and twenty authors were identified as the most influential by being both the most prolific and writing a big proportion of the total published papers. The study demonstrated that the Australian mainstream IS research output was dominated by a very few universities, departments and authors, considerably more so than in North America. However, as the research community grows, this domination is expected to diminish. The Australian research community has had steady growth and has more than doubled researcher numbers between 1993 and 1996. Evidence from collaboration patterns indicated that invisible 
colleges have been present in Australian IS research at least from 1993. However, the IS presence in many universities is fragmented and it seems likely that benefits will arise from rationalising this arrangement.

Australian researchers tended to work collaboratively, and the most common form of collaboration was with just one other researcher from within the same department. It seems likely that many of these collaborations were between supervisor and research student. It was found that Australian IS researchers worked within isolated departmental units with little contact with other disciplines. Where researchers work outside their immediate area of expertise, such a research style is likely to reduce the opportunity for quality research. As IS has an interdisciplinary nature, this is likely to be an obstacle for the future development of the Australian mainstream IS scientific community.

The majority of the papers analysed were authored by Australian academics. There was little evidence of collaboration between the Australian IS academic community and academics or others from outside Australia, an indication that the mainstream IS research invisible colleges that exist are largely limited to Australia. A sizeable degree of collaboration has occurred between and among universities from within Australia which has contributed to the establishment of an IS research tradition, and allows invisible college networks to be traced.

ACIS and AJIS were found to be very largely academic publication outlets, with 84 percent of the papers published being written solely by academics. Little practitioner research was published in the outlets examined. Furthermore, little research collaboration took place between academics and practitioners. If IS is an applied science, academics are going into industry as external observers rather than working with IS personnel already placed in the organisations. This finding may have ramifications for both the quality and methodology of the research conducted, particularly for interpretivist studies.

It was found that the invisible colleges of the Australian non-specialist IS research community were narrow both in their definition and distribution, but were growing. A major implication of the study findings is that Australia is at an early stage in the development of a mainstream IS scientific community. This empirical evidence supports a frequently expressed view.

\section{REFERENCES}

Arnott, D. (1995) Australian Conference on Information Systems: An evolving charter, Version 1.0, in possession of the author.

Cue, D. \& Urquhart, C. (1997) Research Benchmarking Report 1997 (Draft), Department of Information Systems, University of Melbourne.

Culnan, M. (1987) 'Mapping the Intellectual Structure of MIS, 1980-1985: A co-citation analysis", MIS Quarterly, Vol 11, No 3, pp 341-353.

de Solla Price, D. (1961) Science Since Babylon, New Haven: Yale University Press.

de Solla Price, D. (1963) Little Science, Big Science, New York: Columbia University Press.

Farhoomand, A. (1987) "Scientific Progress of Management Information Systems", in R. Galliers (ed.) Information Systems Research: Issues, Methods and Practical Guidelines, Oxford : Blackwell Scientific Publications.

Grover, V., Segars, A. H. \& Simon, S. J. (1992) "An Assessment of Institutional Research Productivity in MIS", Data Base, Vol 11, No 2, pp. 5-8.

Jackson, W. M. \& Nath, R. (1989) "Publication Patterns of MIS Researcher", Interface, Vol 11, No 2, pp 1520.

Keen, P. (1980) "MIS Research: Reference Disciplines and a Cumulative Tradition", Proceedings of the First International Conference On Information Systems, Philadelphia, Research and Education in Information Systems, The Society for MIS, pp 9-18.

King, J. L. (1993) "Editorial Notes", Information Systems Research, Vol 4, No 4, pp 291-298.

Latour, B. (1987) Science in Action: How to Follow Scientists and Engineers Through Society, Milton Keynes: Open University Press.

Lending, D. \& Wetherbe, J. (1992) "Update on MIS Research A profile of leading journals and US universities", Data Base, Vol 23, No 3, pp 5-11.

Lindsey, D. (1980) "Production and Citation Measures in the Sociology of Science: The problems of multiple authorship", Social Studies of Science, Vol 10, pp 145-162.

Niemi, A. (1987) "Institutional Contributions to the Leading Finance Journals, 1975 through 1986: A note", Journal of Finance, Vol 42, No 5, pp 1389-1397.

Orlikowski, W. \& Baroudi, J. (1991) "Studying Information Technology in Organizations: Research approaches and assumptions", Information Systems Research, Vol 2, No 1, pp 1-28.

Ridley, G. (1996) "Establishing Australian IS Research Traditions: Identifying appropriate quality publication outlets and the significance of conference publications", Proceedings of the Australasian Conference on Information Systems, Vol. 2, pp 567-578. 
Shanks, G., Rouse, A. \& Arnott, D. (1993) "A Review of Approaches to Research and Scholarship in Information Systems", Working Papers Series 3/93, Department of Information Systems, Monash University.

Shim, J. P., English, J. B. \& Yoon, J. (1991) "An Examination of Articles in the Eight Leading Management Information Systems Journals: 1980-1988", Socio-Economic Planning Science, Vol 25, No 3, pp 211219.

Standing, C. (1996) "The Journal of Holistic Research in Information Systems; Call for papers", URI http://www.bs.ac.cowan.edu.au/publications/johris.html.

Sutton, D. (1997) "The Eighth Australasian Conference on Information Systems, 1997", URL http://business.city.unisa.edu.au/acis97/.

Vogel, D. \& Wetherbe, J. (1984) "MIS Research: A profile of leading journals and universities", Data Base, Vol 16 , No 1 , pp 3-14.

Walsham, G. (1995) "The Emergence of Interpretivism in IS Research", Information Systems Research, Vol 6, No 4, pp 376-394.

\section{ACIS proceedings}

Monash University (1990) Proceedings of the First Annual Conference on Information Systems, February, Melboume.

University of New South Wales (1991) Proceedings of the Second Annual Conference on Information Systems and Database Special Interest Group, February, Sydney.

MacGregor, R., Clarke, R., Little, S., Gould, T. \& Ang, A. (eds) (1992) Proceedings of the Third Australian Conference on Information Systems, October, Wollongong: Dept. of Business Systems, University of Wollongong.

Department of Commerce, University of Queensland (1993) Proceedings of the 4th Australian Conference on Information Systems, September, Brisbane.

Shanks, G. \& Arnott, D. (eds) (1994) Proceedings of the 5th Australasian Conference on Information Systems, September, Melbourne: Department of Information Systems, Monash University.

Pervan, G. \& Newby, M. (eds) (1995) Proceedings of the 6th Australasian Conference on Information Systems, September, Perth: School of Information Systems, Curtin University.

Keen, C., Urquhart, C. \& Lamp, J. (eds) (1996) Proceedings of the 7th Australasian Conference on Information Systems, December, Hobart: Department Computer Science, University of Tasmania. 